\title{
BMJ Open Biomarkers versus traditional risk factors to predict cardiovascular events in very old adults: cross-validated prospective cohort study
}

\author{
Bert Vaes (D) , ${ }^{1}$ Paulien Indestege, ${ }^{1}$ Tinne Serneels, ${ }^{1}$ Eralda Hegendörfer, ${ }^{1,2}$ \\ Petra G van Peet, ${ }^{3}$ Rosalinde K E Poortvliet, ${ }^{3}$ Pierre Wallemacq, ${ }^{4}$ \\ Jacobijn Gussekloo, ${ }^{3,5}$ Jan Degryse ${ }^{1,2}$
}

To cite: Vaes $B$, Indestege $P$, Serneels T, et al. Biomarkers versus traditional risk factors to predict cardiovascular events in very old adults: cross-validated prospective cohort study. BMJ Open 2020;10:e035809. doi:10.1136/ bmjopen-2019-035809

- Prepublication history and additional material for this paper are available online. To view these files, please visit the journal online (http://dx.doi. org/10.1136/bmjopen-2019035809).

Received 17 November 2019 Revised 22 May 2020 Accepted 28 May 2020

Check for updates

(c) Author(s) (or their employer(s)) 2020. Re-use permitted under CC BY-NC. No commercial re-use. See rights and permissions. Published by BMJ.

For numbered affiliations see end of article.

Correspondence to

Dr Bert Vaes;

bert.vaes@kuleuven.be

\section{ABSTRACT}

Objectives To test new cardiovascular (CV) risk models in very old adults with and without a history of CV disease (CVD), based on traditional risk factors and biomarkers. Design Cross-validated prospective cohort study. The models were tested in the BELFRAIL Study and externally validated in the Leiden 85-plus Study.

Setting General practice, Belgium and The Netherlands. Participants The BELFRAIL cohort consisted of 266 patients aged 80 years or older without a history of CVD and 260 with a history of CVD. The Leiden 85-plus Study consisted of 264 patients aged 85 years without a history of CVD and 282 with a history of CVD.

Outcome measures The model with traditional risk factors and biomarkers, as well as the model using only biomarkers, was compared with the model with only traditional risk factors to predict 3-year CV morbidity and mortality. A competing-risk analysis was performed, and the continuous net reclassification improvement (NRI), integrated discrimination improvement (IDI) and net benefit were used to compare the predictive value of the different models.

Results Traditional risk factors poorly predicted CV mortality and morbidity. In participants without a history of CVD, adding N-terminal pro-B-type natriuretic peptide (NT-pro-BNP) improved the prediction (NRI $0.56(95 \% \mathrm{Cl}$ 0.16 to 0.99 ) and relative IDI 4.01 (95\% Cl 2.19 to 6.28$)$ ). In participants with a history of CVD, the NRI with the addition of NT-pro-BNP and high-sensitivity $\mathrm{C}$ reactive protein was 0.38 (95\% Cl 0.09 to 0.70$)$, and the relative IDI was $0.53(95 \% \mathrm{Cl} 0.23$ to 0.90$)$. Moreover, in participants without a history of CVD, NT-pro-BNP performed well as a stand-alone predictor (NRI $0.32(95 \% \mathrm{Cl}-0.12$ to 0.74$)$ and relative IDI 3.44 (95\% $\mathrm{Cl} 1.56$ to 6.09$)$ ).

Conclusions This study tested new risk models to predict CV morbidity and mortality in very old adults. Especially, NT-pro-BNP showed a strong added predictive value. This opens perspectives for clinicians who are in need of an easily applicable strategy for CV risk prediction in very old adults.

\section{INTRODUCTION}

People aged 80 years and over are the fastest growing age segment in the developed world.
Strengths and limitations of this study

- This study tested new risk models for primary and secondary cardiovascular risk prevention in very old adults using both traditional risk factors and biomarkers.

- Competing-risk time-to event analyses were used, and both internal and external validation were performed.

- Comorbidities may have been underdiagnosed because they were not assessed but were reported by the general practitioner.

- The Leiden 85-plus Study population is quite similar to that of the BELFRAIL study, so further external validation in very old populations might be needed.

By 2050, approximately 1 in 10 individuals living in Belgium will be aged 80 years or older. ${ }^{1}$ Cardiovascular disease (CVD) is a considerable cause of disability, morbidity and mortality, ${ }^{2}$ and CVD status is an important prognostic value in old age. ${ }^{3}$ Therefore, $\mathrm{CV}$ prevention in very old adults is becoming increasingly important. First, early detection and treatment of CVD in very old people without a history of CV events might help preserve cognitive function, independence, functional status and quality of life. ${ }^{2}$ Second, because of better and advanced treatment options for CVD, more patients survive their $\mathrm{CV}$ events, emphasising the importance of secondary CV prevention.

Selection for CV preventive treatment in people aged 80 and over has proven to be very difficult because traditional risk markers lose their predictive value with age or even act in the reverse direction. ${ }^{2}{ }^{4-13}$ Further- $^{-}$ more, pre-existing risk scores and risk charts for primary prevention, such as Systematic COronary Risk Evaluation (SCORE) ${ }^{14}$ Framingham Risk Score, ${ }^{1516}$ QRISK $^{1718}$ and the 
ACC-AHA risk calculator, ${ }^{19}$ were derived from data of middle-aged people and have not been validated in very old adults. However, there is evidence that biomarkers such as N-terminal pro-B-type natriuretic peptide (NT-pro-BNP),${ }^{20-23}$ troponins, ${ }^{24}$ high-sensitivity $\mathrm{C}$ reactive protein (hsCRP),${ }^{525}$ interleukin $6^{510}$ and homocysteine $^{525}$ can be used as predictors of CV morbidity and mortality and can improve the accuracy of risk estimation when added to traditional risk factors in very old adults with or without a history of CVD.

The SMART Risk Score, to predict the 10-year risk of recurrent CV events in patients between 18 and 100 years old with any type of arterial disease, was the first risk calculator to include renal function (estimated glomerular filtration rate (eGFR)) and hs-CRP in addition to all traditional risk markers. ${ }^{26}$ Poortvliet et al compared the traditional CV risk factors and the SMART Risk Score, both with and without NT-pro-BNP, in subjects aged 70-82 years old. They concluded that a model with age, sex and NT-pro-BNP was the most simple and accurate model to predict non-fatal and fatal CV events. ${ }^{27}$

Currently, there are no CV risk models for subjects aged 80 and over with or without a history of CVD. Moreover, there is an increasing need to generate simple, easily applicable risk models for $\mathrm{CV}$ risk prediction in very old adults. ${ }^{4829}$ Therefore, this study was performed as a first step in the development of a new risk model to predict 3-year CV morbidity and mortality in very old adults with or without a history of CVD, based on traditional risk factors and biomarkers (eGFR, NT-pro-BNP and hs-CRP), using data from the BELFRAIL cohort study. ${ }^{30}$ An external validation of the new risk models was performed in the Leiden 85 -plus Study. ${ }^{31}$

\section{METHODS}

\section{Study population}

The BELFRAIL cohort study is an observational population-based prospective cohort study of very old adults in three well-circumscribed areas in Belgium. The study protocol, sampling methods and sample size calculation have been described previously. ${ }^{30}$ Briefly, between November 2008 and September 2009, 567 individuals aged 80 years and older were recruited in 29 general practice centres, excluding only those with severe dementia, medical emergencies or palliative care. At baseline, the general practitioners (GPs) recorded sociodemographic data and medical history. A clinical research assistant performed a standardised assessment at each participant's home, including ECG and blood sample collection. All participants gave informed consent. ${ }^{30}$

\section{Patient and public involvement}

No patients were involved in the development of the research question, study design or interpretation of the data. There are no plans to disseminate the results of the research to study participants or the relevant patient community.

\section{Clinical variables}

The presence of hypertension and diabetes was registered. The history of CVD was expressed as the history

Table 1 Description of the study population $(n=526)$

\begin{tabular}{|c|c|c|}
\hline & $\begin{array}{l}\text { Participants without history of CVD } \\
(\mathrm{n}=266)\end{array}$ & $\begin{array}{l}\text { Participants with history of CVD } \\
(\mathrm{n}=260)\end{array}$ \\
\hline Age, mean $\pm \mathrm{SD}$ (years) & $84.29 \pm 3.57$ & $85.25 \pm 3.79$ \\
\hline Male, n (\%) & $70(26.3)$ & $122(46.9)$ \\
\hline Total cholesterol, mean \pm SD (mg/dL) & $210.52 \pm 42.83$ & $192.42 \pm 42.86$ \\
\hline $\mathrm{HDL}$ cholesterol, mean $\pm \mathrm{SD}$ (mg/dL) & $58.38 \pm 15.87$ & $52.41 \pm 13.42$ \\
\hline Systolic blood pressure, mean $\pm \mathrm{SD}(\mathrm{mm} \mathrm{Hg})$ & $142.25 \pm 20.55$ & $140.80 \pm 19.94$ \\
\hline Current or past smoking, $\mathrm{n}(\%)$ & $61(22.9)$ & $102(39.2)$ \\
\hline Presence of diabetes*, n (\%) & $44(16.5)$ & $56(21.5)$ \\
\hline Presence of hypertensiont, $\mathrm{n}(\%)$ & $184(69.2)$ & $185(71.2)$ \\
\hline Antihypertensive medication $\ddagger$, $\mathrm{n}(\%)$ & $201(75.6)$ & $224(86.2)$ \\
\hline Lipid lowering medication, n (\%) & $69(25.9)$ & $103(39.6)$ \\
\hline History of major cardiovascular event & $0(0)$ & $183(70.4)$ \\
\hline NT-pro-BNP, median (IQR) (pg/mL) & $140.40(77.33-270.45)$ & $253.60(125.00-752.05)$ \\
\hline eGFR, mean $\pm S D(m L / m i n)$ & $67.92 \pm 21.48$ & $59.73 \pm 22.40$ \\
\hline hsCRP, median (IQR) (mg/dL) & $0.188(0.078-0.401)$ & $0.175(0.082-0.431)$ \\
\hline
\end{tabular}

${ }^{*}$ According to the general practitioner or the prescription of blood glucose lowering medication.

†According to the general practitioner.

$\ddagger \beta$-blocker, diuretic, calcium antagonist, ACE inhibitor or AT II receptor antagonist.

CVD, cardiovascular disease; eGFR, estimated glomerular filtration rate; HDL, high-density lipoprotein; hsCRP, high-sensitivity $\mathrm{C}$ reactive

protein; NT-pro-BNP, N-terminal pro-B-type natriuretic peptide. 


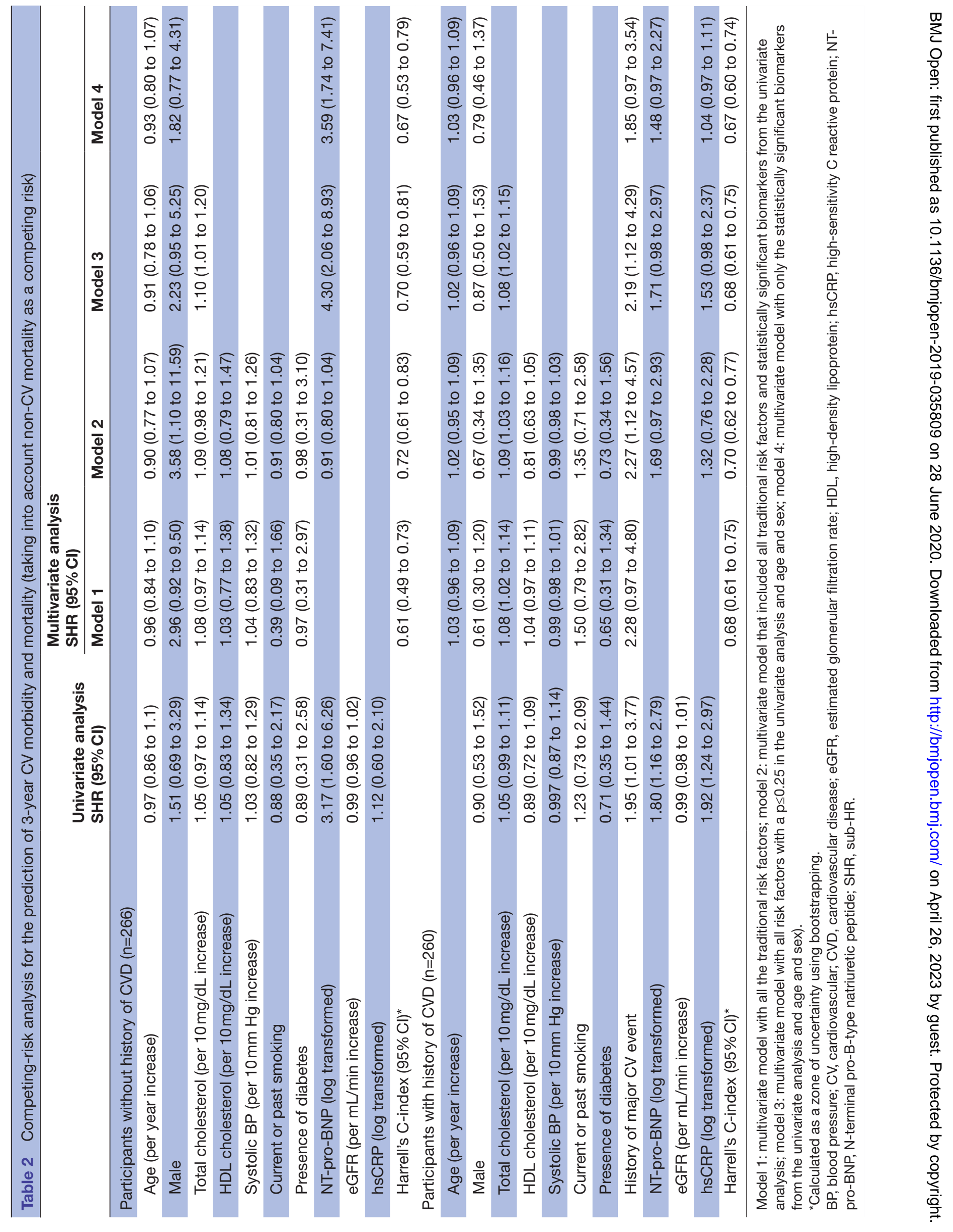


Table 3A Discrimination statistics of the different models for 3-year cardiovascular morbidity and mortality (BELFRAIL data)

\begin{tabular}{|c|c|c|c|c|c|}
\hline & $\begin{array}{l}\mathrm{NRI}_{\text {cf }} \\
(95 \% \text { bootstrap Cl) }\end{array}$ & $\begin{array}{l}\mathrm{NRI}_{\mathrm{cf}} \\
\text { Events, \% }\end{array}$ & $\begin{array}{l}\mathrm{NRI}_{\text {cf }} \\
\text { Non-events, \% }\end{array}$ & $\begin{array}{l}\text { IDI absolute } \\
(95 \% \text { bootstrap CI) }\end{array}$ & $\begin{array}{l}\text { IDI relative } \\
(95 \% \text { bootstrap Cl) }\end{array}$ \\
\hline \multicolumn{6}{|c|}{ Participants without history of CVD $(n=266)$} \\
\hline Model 1 & Reference model & & & & \\
\hline Model 2 & 0.56 (0.16 to 0.99$)$ & 16.7 & 39.6 & 0.10 (0.06 to 0.16$)$ & 4.01 (2.19 to 6.28$)$ \\
\hline Model 3 & $0.42(-0.03$ to 0.86$)$ & 9.8 & 32.1 & 0.09 (0.05 to 0.16$)$ & 3.69 (1.72 to 6.38$)$ \\
\hline Model 4 & $0.32(-0.12$ to 0.74$)$ & 7.5 & 24.3 & 0.09 (0.04 to 0.14$)$ & 3.44 (1.56 to 6.09$)$ \\
\hline \multicolumn{6}{|c|}{ Participants with history of CVD $(n=260)$} \\
\hline Model 1 & Reference model & & & & \\
\hline Model 2 & 0.38 (0.09 to 0.70$)$ & 19 & 19 & $0.03(0.02$ to 0.06$)$ & $0.53(0.23$ to 0.90$)$ \\
\hline Model 3 & $0.09(-0.21$ to 0.40$)$ & 5 & 3.5 & $0.02(0.003$ to 0.04$)$ & 0.33 (0.04 to 0.70$)$ \\
\hline Model 4 & $-0.03(-0.34$ to 0.27$)$ & -2.4 & 0.7 & 0.0004 (-0.02 to 0.02$)$ & $0.006(-0.26$ to 0.35$)$ \\
\hline
\end{tabular}

Participants without history of CVD=model 1: age, sex, systolic BP, total cholesterol, HDL, smoking, diabetes; model 2: age, sex, systolic BP, total cholesterol, HDL, smoking, diabetes, NT-pro-BNP; model 3: age, sex, total cholesterol, NT-pro-BNP; model 4: age, sex, NT-pro-BNP.

Participants with history of CVD=model 1: age, sex, systolic BP, total cholesterol, HDL, smoking, diabetes; model 2: age, sex, systolic BP, total cholesterol, HDL, smoking, diabetes, history of major cardiovascular event, NT-pro-BNP, hsCRP; model 3: age, sex, total cholesterol, history of major cardiovascular event, NT-pro-BNP, hsCRP; model 4: age, sex, NT-pro-BNP, hsCRP. $\mathrm{BP}$, blood pressure; CVD, cardiovascular disease; HDL, high-density lipoprotein; hsCRP, high-sensitivity C reactive protein; IDI, Integrative Discrimination Index; $\mathrm{NRI}_{\mathrm{cf}}$, category-free net reclassification improvement; NT-pro-BNP, N-terminal pro-B-type natriuretic peptide.

of a minor or a major CV event. The history of a minor $\mathrm{CV}$ event was defined as a positive response for a history of angina pectoris, transient ischaemic attack, peripheral arterial disease or an episode of decompensated heart failure. A history of a major CV event was defined as a history of myocardial infarction (reported by the GP or present on the ECG (Minnesota code 1-1 or 1-2, excluding 1-2-8) (QRS Universal ECG device (QRS Diagnostic, Plymouth, USA)), history of stroke or important $\mathrm{CV}$ interventions or surgery (percutaneous transluminal coronary angioplasty or stenting, coronary or arterial surgery). Smoking status was registered.

The Anatomical Therapeutic Chemistry classification system was applied to register medication use. Data on relevant CV medication, including diuretics, $\beta$-blockers, calcium antagonists, ACE inhibitors, angiotensin II receptor blockers and lipid lowering agents, were used.

Blood pressure was measured in the sitting position on both arms with the GP's own blood pressure metre and was repeated once after $2 \mathrm{~min}$. The systolic and diastolic blood pressure (highest value, left or right arm) after 2 min was used in the analyses.

A blood sample was collected in the morning after fasting and plasma (ethylenediaminetetraacetic acid (EDTA)) and serum samples were stored at $-80^{\circ} \mathrm{C}$. Total cholesterol, low-density lipoprotein (LDL) and high-density lipoprotein (HDL) cholesterol, creatinine and hsCRP were measured using the UniCel DxC 800 Synchron (Beckman-Coulter, Brea, USA). eGFR using the MDRD formula. Serum NT-pro-BNP was measured using the Dade-Dimension Xpand (Siemens, Deerfield, USA). The coefficient of variation ranged from $3.9 \%$ to $4.3 \%$.

\section{Outcome}

Three detailed follow-up questionnaires were completed by the participating GPs at $1.4 \pm 0.3,3.0 \pm 0.3$ and $5.1 \pm 0.3$ years after baseline. These questionnaires included questions on mortality and cause of death. The causes of death were divided into CV and non-CV according to the GPs' assessment and subsequent review by two independent researchers blinded to all clinical data. The two first questionnaires also included questions on the incidence of major CV events such as myocardial infarction and stroke. The outcome for the present study was the combination of CV mortality and incident morbidity (myocardial infarction or stroke) 3 years after baseline, whatever came first.

\section{External validation}

The Leiden 85-plus Study is an observational populationbased prospective follow-up study of inhabitants of the city of Leiden, the Netherlands. Participants were aged 85 years at baseline. Between September 1997 and September 1999, all inhabitants of Leiden born between 1912 and 1914 were asked to participate from their 85th birthday onwards. There were no exclusion criteria. At baseline and yearly up to the age of 88 , the participants were visited at their place of residence to take questionnaires, undergo functional tests, give blood samples and record an ECG. Medical history was obtained from the participant's GP or nursing home physician, and incident events between ages 85 and 88 were obtained yearly. All participants provided informed consent. ${ }^{31}$

\section{Data analysis}

Descriptive statistics for baseline characteristics and outcome variables are presented as mean and SD, median 


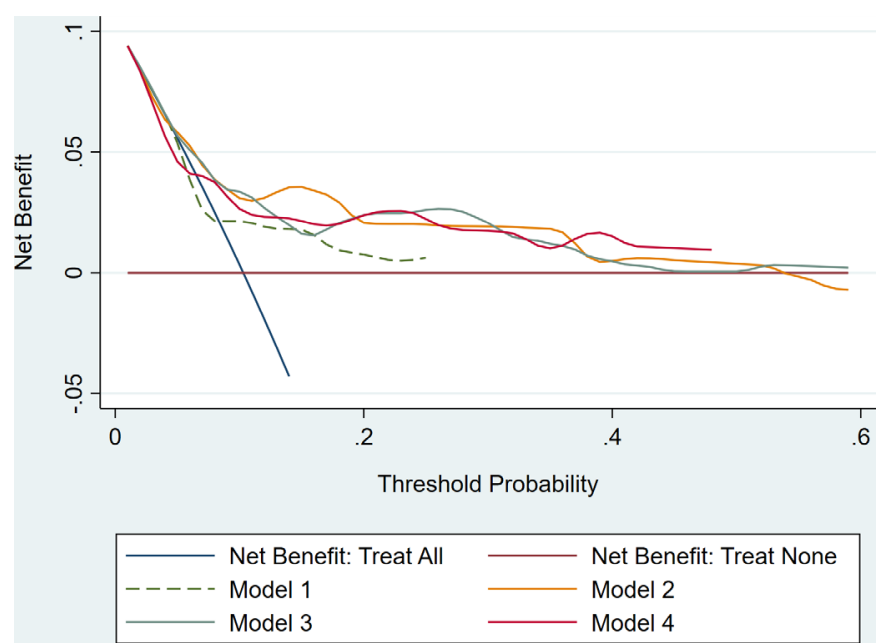

Figure 1 Decision curve: participants without history of CVD (BELFRAIL cohort). CVD, cardiovascular disease.

and IQR or counts and percentages. NT-pro-BNP levels and hsCRP levels were log transformed because of the strongly skewed nature of the data. Cox proportional hazards regression models were used to estimate the HR of individual risk factors for the combined end point of CV mortality and morbidity. To build the different risk models, the following strategy was used: first, a multivariate model with all the traditional risk factors was composed (model 1); second, a multivariate model that included all traditional risk factors and statistically significant biomarkers from the univariate analysis was built (model 2); third, all risk factors with a $\mathrm{p} \leq 0.25$ in the univariate analysis and age and sex were included in the multivariate analyses (model 3); fourth, only the statistically significant biomarkers from the univariate analysis and age and sex were included in the multivariate model (model 4). Models were checked for the proportional hazard assumption. In the case of multicollinearity ( $r$ value $>0.80$ ), only one of the two covariables was considered in the multivariable model. Because non-CV mortality precluded the occurrence of the primary event

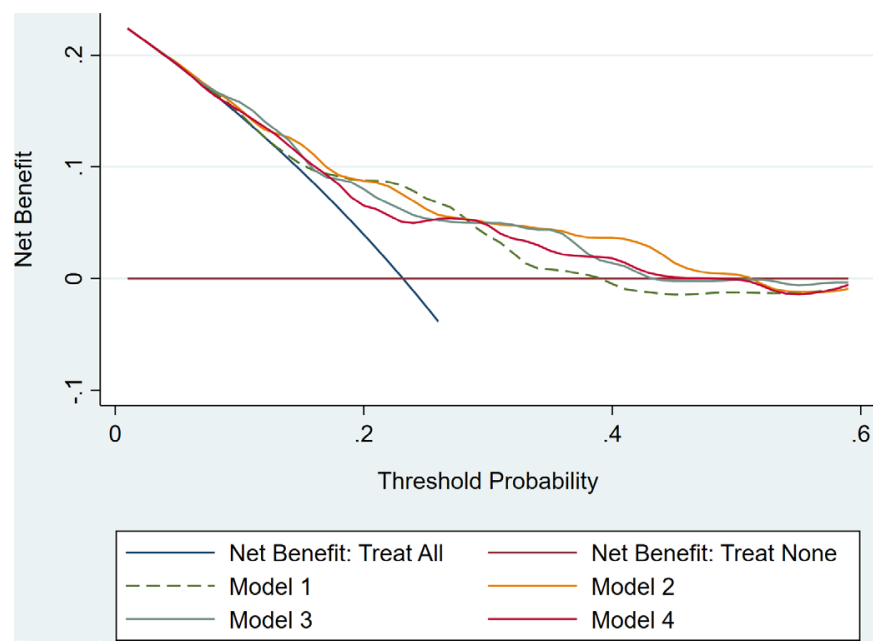

Figure 2 Decision curve: participants with history of CVD (BELFRAIL cohort). CVD, cardiovascular disease. of interest (CV mortality and incident morbidity), we decided to run a competing-risk analysis and to compute the sub-HR (SHR) using the method described by Fine and Gray. ${ }^{32}$ Harrell's C (coefficient of concordance) was calculated as a measure of the ordinal predictive power of each model. ${ }^{33}$ We used a bootstrapping procedure to calculate a 95\% zone of uncertainty around each coefficient as an internal validation procedure.

Furthermore, continuous net reclassification improvement (NRI) and integrated discrimination improvement (IDI) were used to compare the predictive value of the different models using the model with the traditional $\mathrm{CV}$ risk factors as the reference model. The continuous NRI is the sum of the proportion of correctly reclassified subjects for events (NRI events) and non-events (NRI non-events) considering all changes in predicted risk between two models for events and non-events, without a defined risk categorisation. The IDI is the difference in discrimination slopes between two models (absolute IDI) or the difference in discrimination slopes over the slope of the reference model (relative IDI). ${ }^{34-37}$

To evaluate and compare the different prediction models, the net benefit was calculated. The net benefit is the difference between true positives and false positives, weighted by the relative harm of a false positive and a false negative result. ${ }^{38}$ The net benefit for each model was calculated over all possible risk categories and compared against two clinical alternatives using a prediction model: considering all participants as positive and applying a treatment or intervention ('treat all') or considering all participants as negative and applying no treatment or intervention ('treat none'). The prediction model claimed to be better at predicting an outcome should have a higher net benefit than the 'treat all' and 'treat none' alternatives and the other competing models. Decision curves were constructed by plotting the net benefit of the competing models (vertical axis) across the range of risk categories for the outcome (range 0.05-0.50) (horizontal axis). ${ }^{38-40}$ Decision curve analysis complements and adjusts conclusions based on just statistical measures such as NRI, IDI and Harrell's C index. It is a simple way of giving an answer to the question of which model would lead to a better clinical outcome.

Finally, an external validation of the four models was performed in the Leiden 85-plus Study population. Harrell's C, discrimination statistics and decision curves of the different models were calculated in the Leiden population.

Statistical analysis was performed with Stata V.13.0 (StataCorp) and SAS University Edition (SAS Institute).

\section{RESULTS}

The initial BELFRAIL cohort consisted of 566 participants. At baseline, 286 of them did not have a history of CVD, and 280 had a history of CVD. All variables were available for $93 \%$ of participants in each subset. Table 1 shows the description of the study population. 
Table 3B Discrimination statistics of the different models for 3-year cardiovascular morbidity and mortality (Leiden 85-plus study)

\begin{tabular}{lllll}
$\mathrm{NRI}_{\mathrm{cf}}$ & $\mathrm{NRI}_{\mathrm{cf}}$ & $\mathrm{NRI}_{\mathrm{cf}}$ & IDI absolute & IDI relative \\
$(\mathbf{9 5 \%}$ bootstrap CI) & Events, \% & Non-events, \% & (95\% bootstrap CI) & (95\% bootstrap Cl) \\
\hline
\end{tabular}

\begin{tabular}{|c|c|c|c|c|c|}
\hline \multicolumn{6}{|c|}{ Participants without history of CVD $(n=264)$} \\
\hline Model 1 & Reference model & & & & \\
\hline Model 2 & 0.47 (0.14 to 0.82$)$ & 17.84 & 29.9 & 0.06 (0.04 to 0.08$)$ & 5.21 (3.52 to 7.26$)$ \\
\hline Model 4 & $0.27(-0.08$ to 0.57$)$ & 15.97 & 11.38 & $0.04(0.02$ to 0.05$)$ & 3.37 (2.09 to 5.07$)$ \\
\hline \multicolumn{6}{|c|}{ Subjects with history of CVD $(n=282)$} \\
\hline Model 2 & $0.42(0.15$ to 0.69$)$ & 14.03 & 28.37 & $0.10(0.07$ to 0.13$)$ & $1.36(0.98$ to 1.79$)$ \\
\hline Model 3 & 0.46 (0.20 to 0.72$)$ & 17.93 & 28.10 & 0.11 (0.08 to 0.15$)$ & $1.52(1.06$ to 2.05$)$ \\
\hline Model 4 & $0.48(0.22$ to 0.74$)$ & 22.60 & 26.12 & $0.11(0.08$ to 0.14$)$ & 1.45 (0.99 to 2.00$)$ \\
\hline
\end{tabular}

Participants without history of CVD=model 1: sex, systolic BP, total cholesterol, HDL, smoking, diabetes; model 2: sex, systolic BP, total cholesterol, HDL, smoking, diabetes, NT-pro-BNP; model 3: sex, total cholesterol, NT-pro-BNP; model 4: sex, NT-pro-BNP. Participants with history of CVD=model 1: sex, systolic BP, total cholesterol, HDL, smoking, diabetes; model 2: sex, systolic BP, total cholesterol, HDL, smoking, diabetes, history of major cardiovascular event, NT-pro-BNP, hsCRP; model 3: sex, total cholesterol, history of major cardiovascular event, NT-pro-BNP, hsCRP; model 4: sex, NT-pro-BNP, hsCRP.

CVD, cardiovascular disease; IDI, Integrative Discrimination Index; $\mathrm{NRI}_{\mathrm{cf}}$, category-free net reclassification improvement.

Follow-up data were available for all participants. After 3 years, 37 participants $(7.0 \%)$ developed a CV event, and $56(10.6 \%)$ died due to a CV cause. The combined end point was present in 26 participants $(9.8 \%)$ without a history of CVD and in $56(21.5 \%)$ with a history of CVD.

Multicollinearity was found between total cholesterol and LDL-cholesterol $(\mathrm{r}=0.94, \mathrm{p}<0.001)$. All further analyses were done with only total cholesterol.

\section{Models in participants without history of CVD}

The univariate regression analysis showed a strong association between log-transformed NT-pro-BNP levels and the combined end point (SHR 3.17 (95\% CI 1.60 to 6.26)). Additionally, total cholesterol was associated with the combined end point (SHR 1.05 (95\% CI 0.97 to 1.14)). Four different multivariate models were built as described in the Methods section (table 2). The Harrell's C statistics of the different models were comparable.

Table 3A presents discrimination statistics of the different models for 3-year CV mortality and morbidity with model 1 as the reference model. Based on the risk reclassification improvement measures (NRI and IDI), compared with model 1, model 2 improved the risk reclassification for $16.7 \%$ of participants with an event and $39.6 \%$ of participants without an event. This can be interpreted as $56 \%$ of the subjects being better classified with respect to the baseline model. Model 3 improved the risk reclassification for $9.8 \%$ of patients with an event and $32.1 \%$ of patients without an event, while model 4 improved the risk reclassification for $7.5 \%$ of participants with an event and $24.3 \%$ of participants without an event. Overall, compared with model 1, model 2, with the addition of NT-pro-BNP, had the highest relative IDI for 3-year CV mortality and morbidity (4.01), increasing the difference in mean predicted probability of events and non-events by $401 \%$. Model 3 and model 4 also showed very high relative IDIs.

Figure 1 shows the decision curve analyses. Models 2-4 showed a higher net benefit in each risk category compared with model 1 and were similar to each other. Depending on the risk category, models 2 or 3 or 4 showed the highest net benefit. Overall, models 2-4 were shown to be models of higher clinical value and had higher rates of avoiding unnecessary 'treatment' in comparison with the traditional CV risk model.

\section{Models in participants with a history of CVD}

Univariate regression analysis showed significant associations between total cholesterol, history of major CV events, NT-pro-BNP and hsCRP and the combined end point (table 2).

Differences in Harrell's C statistic were not significant between the different models. Based on the risk reclassification improvement measures, compared with model 1, model 2 improved the risk reclassification for $19 \%$ of patients with an event and $19 \%$ of patients without an event. This gave a total improvement in risk reclassification of $38 \%$. Models 3 and 4 did not show a significantly improved risk reclassification compared with model 1. Overall, compared with model 1, model 2 had the highest relative IDI for 3-year CV mortality and morbidity (0.53), increasing the difference in mean predicted probability of events and non-events by $53 \%$. Model 3 also showed a high relative IDI.

Figure 2 shows the decision curve analysis. Overall, model 2 had the highest net benefit, although model 1 was the model with the highest net benefit, at a risk probability of $0.20-0.27$. 


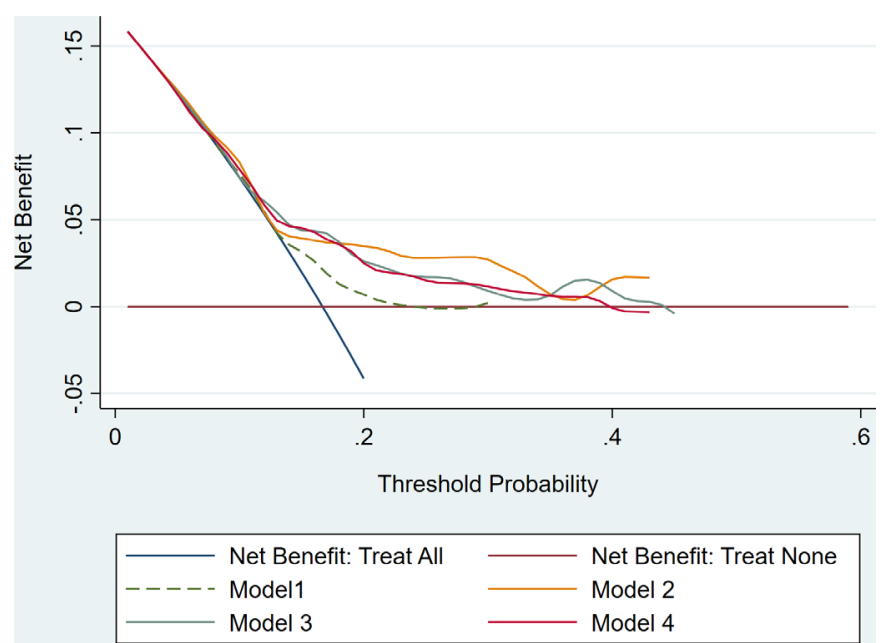

Figure 3 Decision curve: participants without history of CVD (Leiden 85+ cohort). CVD, cardiovascular disease.

\section{External validation}

The online supplementary table shows the results of a competing-risk regression analysis for the prediction of 3-year CV morbidity and mortality in the Leiden cohort (taking into account non-CV mortality as a competing risk) and using the same predictors as in the BELFRAIL risk model(s) except for age, since all participants had the same age at baseline. Table 3B and figures 3 and 4 show the discrimination statistics and the decision curves as applied to the data of the Leiden 85-plus Study. The results of these analyses appear to be similar to the findings in the BELFRAIL cohort.

\section{DISCUSSION}

\section{Main findings}

This study tested new CV risk models for very old adults with and without a history of CVD. We found that traditional CV risk factors were poor predictors of 3-year CV mortality and morbidity. However, the addition of biomarkers such as NT-pro-BNP and hs-CRP

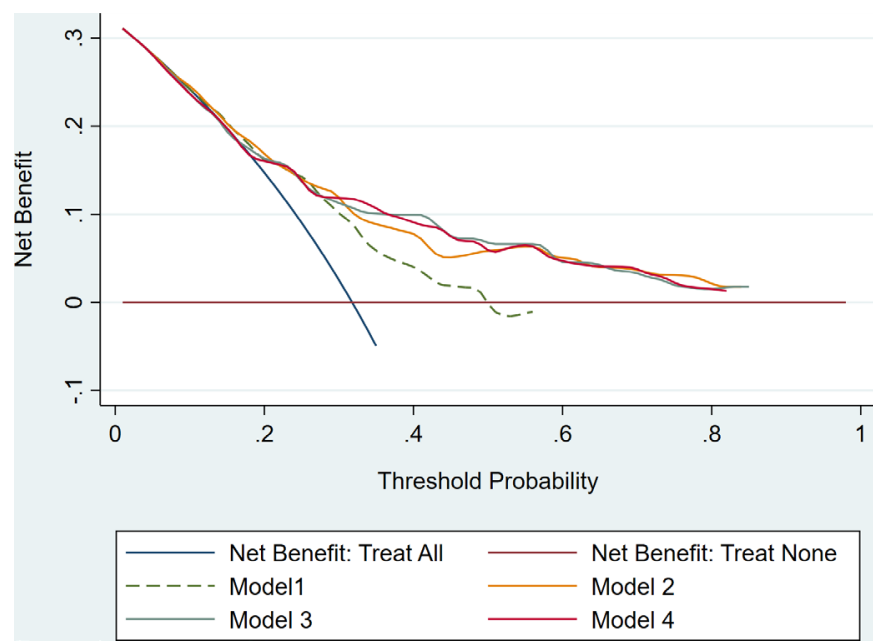

Figure 4 Decision curve: participants with history of CVD (Leiden 85+ cohort). CVD, cardiovascular disease. significantly improved the prediction of CV mortality and morbidity. Moreover, in participants without a history of CVD, NT-pro-BNP performed very well as a stand-alone predictor. This study emphasises the high clinical value of biomarkers such as NT-pro-BNP in predicting 3 years $\mathrm{CV}$ mortality and morbidity in very old adults.

\section{Comparison with previous research}

Risk prediction models in very old adults without a history of CVD Our results are in line with other observational studies showing that traditional CV risk factors lose their predictive value in very old adults. ${ }^{2}{ }^{5}$ 7-10 12 On the other hand, biomarkers, especially NT-pro-BNP, become more important in old age for different reasons. First, NT-pro-BNP remains a disease-specific marker of cardiac illness, even in very old adults. ${ }^{21}$ Low levels of NT-pro-BNP can be used to exclude echocardiographic abnormalities in very old age. ${ }^{41}$ Second, NT-pro-BNP has been shown to predict mortality and CV events. ${ }^{21}{ }^{42}$ Moreover, the prognostic information from NT-pro-BNP is independent of traditional $\mathrm{CV}$ risk factors, prevalent CVD, left ventricular dysfunction and renal function. ${ }^{20}{ }^{42}$ Elevated NT-pro-BNP in very old patients without previous hospitalisations for cardiac disease or evidence of heart failure may be caused by occult conditions, such as asymptomatic heart failure, atrial fibrillation, myocardial hypertrophy and left ventricular diastolic dysfunction, all of which are common in older adults. ${ }^{43}$

Other studies have shown that adding biomarkers to a model consisting of traditional risk markers improved the risk prediction in older adults. ${ }^{10}{ }^{44}$ However, these studies had a lower mean age of the population ( 71 and 78 years old) and included only male participants. Our study confirms the value of adding biomarkers for predicting $\mathrm{CV}$ risk in adults aged 80 and over without a history of CVD.

\section{Risk prediction models in very old adults with a history of CVD}

In our study, although overall the traditional CV risk factors showed a lower predictive value, the history of a major CV event and the level of total cholesterol were significantly associated with the combined end point in all models. The importance of the severity of a previous event has been proven in younger patients ${ }^{45} 46$ but also in very old adults. ${ }^{2}$ In subjects aged 85 and older, van Peet $e t$ al demonstrated that a history of a minor event conferred only half the risk of having a recurrent event compared with a history of a major event. The association we observed between cholesterol and the combined end point is in contrast with the findings of Weverling-Rijnsburger et al, who concluded that total cholesterol is not a significant risk marker for CV mortality in older subjects with a history of CVD. They found that only low HDL-cholesterol was a risk factor for fatal coronary artery disease and stroke, not high LDL or high total cholesterol. ${ }^{47}$

Previous studies also found that adding biomarkers to the traditional risk markers gave better and more correct risk stratification. ${ }^{48}{ }^{49}$ Zengin et al found that diabetes was 
the strongest predictor of all traditional $\mathrm{CV}$ risk markers for a recurrent $\mathrm{CV}$ event and identified an added value of CRP. However, they did not add NT-pro-BNP as a biomarker, and they only studied participants with a history of coronary diseases. ${ }^{49}$ On the other hand, in the SAVOR TIMI 53 trial in subjects with diabetes and overt CVD aged between 39 and 99 years old, Scirica et al added NT-pro-BNP as a biomarker and observed that adding high-sensitivity troponin T, NT-pro-BNP or hsCRP to the classical clinical variables improved the prediction of $\mathrm{CV}$ death, myocardial infarction and hospitalisation for heart failure. ${ }^{48}$ In the PROSPER trial, Poortvliet et al concluded that NT-pro-BNP was the strongest biomarker to add to traditional $\mathrm{CV}$ risk markers to predict CV mortality and morbidity in secondary prevention. ${ }^{27}$ However, the results of the current study do not harmonise from all perspectives with the results from the PROSPER data. Poortvliet et al concluded that the model based on age, sex and NT-pro-BNP was the most simple and accurate model to predict the 2.5 years risk of fatal and non-fatal CV events in subjects aged between 70 and 82 years old with a history of CVD. ${ }^{27}$ The current study confirmed that the simple models were better than the model based on the traditional risk factors in the Leiden 85-plus Study cohort, but not in the BELFRAIL cohort. This difference might be explained by the differences in study population: the data from PROSPER and Leiden 85-plus Study were collected 10 years before the BELFRAIL study population.

\section{Implications for practice and future research}

Our study illustrates the risk factor paradox in very old adults, showing that traditional CV risk factors lose their predictive value. Possibly, the poor predictive value of traditional risk factors is a reflection of different metabolism and homeostatic mechanisms in middle-aged people compared with very old ones. Furthermore, the status of traditional CV risk markers in very old adults does not necessarily reflect the lifetime status and evolution of these markers, and thus, they are not able to effectively stratify $\mathrm{CV}$ risk in old age.

We showed that adding biomarkers to traditional risk factors would improve the risk stratification in primary and secondary prevention in very old adults. Biomarkers may represent a simple and easily applicable strategy for $\mathrm{CV}$ risk prediction in very old adults. Better identification of patients at high risk for CV events will lead to more accurate selection of patients who might benefit from specific pharmaceutical or non-pharmaceutical treatment strategies. Therefore, future research should focus on developing easy-to-use risk scores for very old adults in daily practice and investigating the effect of treatment or treatment intensification in better-identified patients at risk. Also the impact of an intervention on the levels of biomarkers and the possibility to monitor the effect of the intervention by serial measurements of these biomarkers remains to be investigated.

\section{Strengths and limitations}

This study has several strengths. This is one of the few studies that tested new risk models to predict 3-year CV mortality and morbidity in very old adults with or without a history of CVD based on traditional risk factors and biomarkers. We used competing-risk time-to event analyses, and both internal and external validation were performed.

A few limitations should be noted. First, although started 10 years before, the Leiden 85-plus Study population is quite similar to that of the BELFRAIL study. The similarities between these two populations may be seen as a disadvantage, and further external validation in very old populations might be needed. Second, comorbidities may have been underdiagnosed because they were not assessed but were reported by the GP. Third, the misclassification of the causes of death into $\mathrm{CV}$ and non-CV causes could be a limitation, but this classification was reviewed by two independent researchers blinded to all clinical data. Fourth, the outcomes were GP reported and were not derived from standardised information systems. However, GPs intensively follow very old adults in Belgium. In this regard GPs are best placed to report the cause of death of their patients. Furthermore, the cause of death of old persons that can be found in the offical death statististics in Belgium is often registered by their GP. Fifth, only 3-year risk models were tested. However, the incidence of $\mathrm{CV}$ morbidity and the risk of mortality is high at an average age of 85 years. Also the impact of CV morbidity on the quality of life is large. Therefore, 3-year risk prediction models were considered relevant in this age segment.

\section{CONCLUSION}

We cannot rely on pre-existing risk scores and charts to predict CV mortality and morbidity in people aged 80 and over. This study tested new risk models for primary and secondary CV risk prevention in very old adults using both traditional risk factors and biomarkers. Traditional $\mathrm{CV}$ risk factors poorly predicted 3-year CV mortality and morbidity, but biomarkers such as NT-pro-BNP and hs-CRP showed a strong added predictive value in subjects with and without a history of CV events. Furthermore, in subjects without a history of CVD, NT-pro-BNP performed very well as a stand-alone predictor. This opens new perspectives for clinicians who are in need of a simple, easily applicable strategy for $\mathrm{CV}$ risk prediction in very old adults.

\section{Author affiliations}

${ }^{1}$ Department of Public Health and Primary Care, KU Leuven, Leuven, Belgium ${ }^{2}$ Institute of Health and Society, Université catholique de Louvain (UCL), Brussels, Belgium

${ }^{3}$ Department of Public Health and Primary Care, Leiden University Medical Center, Leiden, The Netherlands

${ }^{4}$ Laboratory of Analytical Biochemistry, Cliniques Universitaires St Luc, Université catholique de Louvain (UCL), Brussels, Belgium 
${ }^{5}$ Department of Internal Medicine, Section Gerontology and Geriatrics, Leiden University Medical Center, Leiden, The Netherlands

Acknowledgements This study was made possible by the participating GPS.

Contributors EH, BV and JD performed the analyses and BV, PI and TS wrote the manuscript. BV, JD and JG are responsible for the study concept and design and the recruitment of subjects and acquisition of data. BV, PI, TS, EH, PGvP, RKEP, PW, JG and JD participated in the interpretation of the data. BV, PI, TS, EH, PGvP, RKEP, PW, $J G$ and JD approved the final version of the manuscript.

Funding The BELFRAIL study (B40320084685) was supported by an unconditiona grant from the Fondation Louvain. The Fondation Louvain is the support unit of the Université catholique de Louvain and is charged with developing the educational and research projects of the university by collecting gifts from corporations, foundations and alumni.

Competing interests None declared.

Patient and public involvement Patients and/or the public were not involved in the design, or conduct, or reporting, or dissemination plans of this research.

\section{Patient consent for publication Not required.}

Ethics approval The study complies with the Declaration of Helsinki, and the Biomedical Ethics Committee of the Medical School of the Université catholique de Louvain (UCL), Brussels, Belgium, approved the study protocol (B40320084685). The Medical Ethics Committee of the Leiden University Medical Centre approved the study.

Provenance and peer review Not commissioned; externally peer reviewed.

Data availability statement Data may be obtained from a third party and are not publicly available. Data may be obtained from the BELFRAlL study. Contact details: Academisch Centrum Huisartsgeneeskunde, KU Leuven, Address: Kapucijnenvoer 33, blok J, bus 7001, 3000 Leuven, E-mail: bert.vaes@kuleuven.be.

Open access This is an open access article distributed in accordance with the Creative Commons Attribution Non Commercial (CC BY-NC 4.0) license, which permits others to distribute, remix, adapt, build upon this work non-commercially, and license their derivative works on different terms, provided the original work is properly cited, appropriate credit is given, any changes made indicated, and the use is non-commercial. See: http://creativecommons.org/licenses/by-nc/4.0/.

ORCID iD

Bert Vaes http://orcid.org/0000-0001-5244-1930

\section{REFERENCES}

1 Pacolet $\mathrm{J}$, Deliège $\mathrm{D}$, Artoisenet $\mathrm{C}$, et al. Vieillissement, aide et soins de santé en Belgique. Rapport pour le SPF securité sociale direction générale politique sociale, 2004.

2 van Peet PG, de Craen AJM, Gussekloo J, et al. Plasma NT-proBNP as predictor of change in functional status, cardiovascular morbidity and mortality in the oldest old: the Leiden 85-plus study. Age 2014;36:9660.

3 van Peet PG, Drewes YM, de Craen AJM, et al. Prognostic value of cardiovascular disease status: the Leiden 85-plus study. Age 2013;35:1433-44.

4 Sabayan B, Gussekloo J, de Ruijter W, et al. Framingham stroke risk score and cognitive impairment for predicting first-time stroke in the oldest old. Stroke 2013;44:1866-71.

5 de Ruijter W, Westendorp RGJ, Assendelft WJJ, et al. Use of Framingham risk score and new biomarkers to predict cardiovascular mortality in older people: population based observational cohort study. BMJ 2009;338:a3083.

6 Muller M, Smulders YM, de Leeuw PW, et al. Treatment of hypertension in the oldest old: a critical role for frailty? Hypertension 2014:63:433-41.

7 Casiglia E, Palatini P. Cardiovascular risk factors in the elderly. J Hum Hypertens 1998:12:575-81.

8 Poortvliet RKE, Blom JW, de Craen AJM, et al. Low blood pressure predicts increased mortality in very old age even without heart failure: the Leiden 85-plus study. Eur J Heart Fail 2013;15:528-33.

9 van Bemmel T, Gussekloo J, Westendorp RGJ, et al. In a population-based prospective study, no association between high blood pressure and mortality after age 85 years. $J$ Hypertens 2006;24:287-92.

10 Störk S, Feelders RA, van den Beld AW, et al. Prediction of mortality risk in the elderly. Am J Med 2006;119:519-25.
11 Lernfelt B, Svanborg A. Change in blood pressure in the age interval 70-90. Late blood pressure peak related to longer survival. Blood Press 2002;11:206-12.

12 Schatz IJ, Masaki K, Yano K, et al. Cholesterol and all-cause mortality in elderly people from the Honolulu heart program: a cohort study. Lancet 2001;358:351-5.

13 Uthoff H, Staub D, Socrates T, et al. PROCAM-, FRAMINGHAM-, SCORE- and SMART-risk score for predicting cardiovascular morbidity and mortality in patients with overt atherosclerosis. VASA 2010;39:325-33.

14 Conroy RM, Pyörälä K, Fitzgerald AP, et al. Estimation of ten-year risk of fatal cardiovascular disease in Europe: the SCORE project. Eur Heart $J$ 2003;24:987-1003.

15 Anderson KM, Wilson PW, Odell PM, et al. An updated coronary risk profile. A statement for health professionals. Circulation 1991;83:356-62.

16 Anderson KM, Odell PM, Wilson PW, et al. Cardiovascular disease risk profiles. Am Heart J 1991;121:293-8.

17 Collins GS, Altman DG. Predicting the 10 year risk of cardiovascular disease in the United Kingdom: independent and external validation of an updated version of QRISK2. BMJ 2012;344:e4181.

18 Hippisley-Cox J, Coupland C, Vinogradova Y, et al. Derivation and validation of QRISK, a new cardiovascular disease risk score for the United Kingdom: prospective open cohort study. BMJ 2007;335:136.

19 Goff DC, Lloyd-Jones DM, Bennett G, et al. 2013 ACC/AHA guideline on the assessment of cardiovascular risk: a report of the American College of Cardiology/American heart association Task force on practice guidelines. Circulation 2014;129:S49-73.

20 Poortvliet R, de Craen A, Gussekloo J, et al. Increase in N-terminal pro-brain natriuretic peptide levels, renal function and cardiac disease in the oldest old. Age Ageing 2015;44:841-7.

21 Vaes B, de Ruijter W, Degryse J, et al. Clinical relevance of a raised plasma N-terminal pro-brain natriuretic peptide level in a populationbased cohort of nonagenarians. J Am Geriatr Soc 2009;57:823-9.

22 Wannamethee SG, Welsh P, Lowe GD, et al. N-terminal pro-brain natriuretic peptide is a more useful predictor of cardiovascular disease risk than C-reactive protein in older men with and without pre-existing cardiovascular disease. J Am Coll Cardiol 2011;58:56-64.

23 Di Angelantonio E, Chowdhury R, Sarwar N, et al. B-type natriuretic peptides and cardiovascular risk: systematic review and metaanalysis of 40 prospective studies. Circulation 2009;120:2177-87.

24 Eggers KM, Al-Shakarchi J, Berglund L, et al. High-sensitive cardiac troponin $\mathrm{T}$ and its relations to cardiovascular risk factors, morbidity, and mortality in elderly men. Am Heart J 2013;166:541-8.

25 van Peet PG, Drewes YM, de Craen AJM, et al. NT-proBNP best predictor of cardiovascular events and cardiovascular mortality in secondary prevention in very old age: the Leiden 85 -plus study. PLoS One 2013;8:e81400.

26 Dorresteijn JAN, Visseren FLJ, Wassink AMJ, et al. Development and validation of a prediction rule for recurrent vascular events based on a cohort study of patients with arterial disease: the smart risk score. Heart 2013;99:866-72.

27 Poortvliet RK, van Peet PG, de Craen AJ, et al. Risk stratification and treatment effect of statins in secondary cardiovascular prevention in old age: additive value of $\mathrm{N}$-terminal pro-B-type natriuretic peptide. Eur J Prev Cardiol 2016;23:1104-13.

28 Cooney MT, Selmer R, Lindman A, et al. Cardiovascular risk estimation in older persons: score O.P. Eur J Prev Cardiol 2016;23:1093-103.

29 Cooney MT, Dudina A, D'Agostino R, et al. Cardiovascular riskestimation systems in primary prevention: do they differ? Do they make a difference? Can we see the future? Circulation 2010;122:300-10.

30 Vaes B, Pasquet A, Wallemacq P, et al. The BELFRAIL (BFC80+) study: a population-based prospective cohort study of the very elderly in Belgium. BMC Geriatr 2010;10:39.

31 der Wiel AB-van, van Exel E, de Craen AJM, et al. A high response is not essential to prevent selection bias: results from the Leiden 85plus study. J Clin Epidemiol 2002;55:1119-25.

32 Fine JP, Gray RJ. A proportional hazards model for the Subdistribution of a competing risk. J Am Stat Assoc 1999;94:496-509.

33 Harrell FE, Lee KL, Mark DB. Multivariable prognostic models: issues in developing models, evaluating assumptions and adequacy, and measuring and reducing errors. Stat Med 1996;15:361-87.

34 Pencina MJ, D'Agostino RB, Steyerberg EW. Extensions of net reclassification improvement calculations to measure usefulness of new biomarkers. Stat Med 2011:30:11-21. 
35 Pencina MJ, D'Agostino RB, Pencina KM, et al. Interpreting incremental value of markers added to risk prediction models. Am J Epidemiol 2012;176:473-81.

36 Van Calster B, Vickers AJ, Pencina MJ, et al. Evaluation of markers and risk prediction models: overview of relationships between NRI and decision-analytic measures. Med Decis Making 2013;33:490-501.

37 Pencina MJ, D'Agostino RB, D'Agostino RB, et al. Evaluating the added predictive ability of a new marker: from area under the ROC curve to reclassification and beyond. Stat Med 2008;27:157-72.

38 Vickers AJ, Elkin EB. Decision curve analysis: a novel method for evaluating prediction models. Med Decis Making 2006;26:565-74.

39 Vickers AJ, Van Calster B, Steyerberg EW. Net benefit approaches to the evaluation of prediction models, molecular markers, and diagnostic tests. BMJ 2016;352:i6.

40 Fitzgerald M, Saville BR, Lewis RJ. Decision curve analysis. JAMA 2015;313:409-10.

41 Vaes B, Delgado V, Bax J, et al. Diagnostic accuracy of plasma NTproBNP levels for excluding cardiac abnormalities in the very elderly. BMC Geriatr 2010;10:85.

42 Kistorp C, Raymond I, Pedersen F, et al. N-terminal pro-brain natriuretic peptide, C-reactive protein, and urinary albumin levels as predictors of mortality and cardiovascular events in older adults. JAMA 2005;293:1609-16.
43 Ueda R, Yokouchi M, Suzuki T, et al. Prognostic value of high plasma brain natriuretic peptide concentrations in very elderly persons. $A m ~ J$ Med 2003;114:266-70.

44 Zethelius B, Berglund L, Sundström J, et al. Use of multiple biomarkers to improve the prediction of death from cardiovascular causes. N Engl J Med 2008;358:2107-16.

45 Rosengren A, Wilhelmsen L, Hagman M, et al. Natural history of myocardial infarction and angina pectoris in a general population sample of middle-aged men: a 16-year follow-up of the primary prevention study, Göteborg, Sweden. J Intern Med 1998;244:495-505

46 Arima $\mathrm{H}$, Tzourio $\mathrm{C}$, Butcher $\mathrm{K}$, et al. Prior events predict cerebrovascular and coronary outcomes in the progress trial. Stroke 2006;37:1497-502.

47 Weverling-Rijnsburger AWE, Jonkers IJAM, van Exel E, et al. Highdensity vs low-density lipoprotein cholesterol as the risk factor for coronary artery disease and stroke in old age. Arch Intern Med 2003;163:1549-54

48 Scirica BM, Bhatt DL, Braunwald E, et al. Prognostic implications of biomarker assessments in patients with type 2 diabetes at high cardiovascular risk: a secondary analysis of a randomized clinical trial. JAMA Cardiol 2016;1:989-98.

49 Zengin E, Bickel C, Schnabel RB, et al. Risk factors of coronary artery disease in secondary prevention - results from the AtheroGene--Study. PLoS One 2015;10:e0131434. 